\title{
Are We Headed toward Another Global Tech Bust?
}

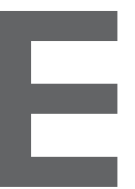

NROLLMENTS IN COMPUTINGRELATED undergraduate degree programs are booming, about to establish a new record in North America. There is also a growing demand for computing courses by students who are not computing majors. In the U.S., President Obama recently announced a new $\$ 4$ billion initiative "to empower students with the computer science skills they need to thrive in a digital economy." Of course, this popularity does not come without costs. The growing size of computing degree programs is clearly stressing academic units and putting pressure on the quality of education provided to students. In response to the insatiable demand, academic institutions are raising their level of investment in computing programs, but academic hiring is agonizingly slow!

What is driving the computingenrollment boom is undoubtedly the global technology boom, epitomized by the global rise of "unicorns" - tech startups with a valuation of at least $\$ 1$ billion. Fortune magazine recently wrote "The billion-dollar technology startup was once the stuff of myth. Today they're seemingly everywhere, backed by a bull market and a new generation of disruptive technology." In January 2016, more than 170 companies were on the unicorn list. It is the dream of joining a unicorn that probably attracts many students to study computing.

We must remember, however, we have witnessed such booms in the past; the history of computing education is a history of booms and busts. Computing-related degree programs were introduced in the mid-to-late 1960s, and grew slowly during the 1970s. The in- troduction of the IBM PC in 1981 made computing a household phenomenon and triggered the tech and enrollment boom in the 1980s. That boom was ended by a recession of the early 1990s.

By the mid-1990s, the Internet and the World-Wide Web had become household names, launching the dot-com boom; the growing popularity of the "Web" led to the founding of many Internet-based companies, commonly referred to as "dot-coms." The NASDAQ Composite Index, a U.S. stock-market index that includes many tech companies, more than quintupled between 1995 and 2000 . The excitement about the new technology and the demand from the job market led to a growing popularity of computing education; enrollments in North America nearly tripled between 1995 and 2000. Surging enrollments were stressing academic units, forcing institutions to increase staffing in those stressed units.

But by 1999 it was becoming increasingly clear the boom had become a speculative bubble. The NASDAQ Index peaked on March 10, 2000, declining almost $80 \%$ over the next two years. Numerous start-up companies went under, bringing down with them several telecommunication companies. The stock-market crash in the U.S. caused the loss of $\$ 5$ trillion in the market valuations from March 2000 to October 2002.

At the same time, the Internet and the Web enabled the globalization of software production, giving rise to the phenomenon of offshore outsourcing. There were daily stories in the media describing major shifts in employment that were occurring largely as a result of offshoring. Combined with the impact of the end of the dot-com boom, these reports raised concerns about the future of computing as a viable field of study and work in developed countries. Computing enrollments in North America went into a steep dive, declining by more than 50\% between 2004 and 2009 .

I believe it is important to remember this history as we celebrate the rise of the unicorns. There are already some indications the current tech boom may be nearing its end. The media has started commenting "The signs of a new tech bubble are everywhere: easy money, widespread exuberance, hidden leverage, and mass participation by amateur investors." What turns a bubble into a bust is a change in investors' psychology. History tells us it does not take much for such a change to occur. The decline of stock markets around the world over the past few months suggests such a change may already be taking place. It is quite likely, also, that a tech bust would bring with it an enrollment bust.

So we should brace ourselves for another global tech and enrollment bust, but also keep in mind the longterm trend. At the trough of 2009, computing enrollments were higher than they were in 1995, before the start of the dot-com boom. Furthermore, a computing degree positions a graduate for solid career opportunities in almost every sector of the global economy, and not only in the tech sector. In the long term, computing is ascendant and will continue to shape the $21^{\text {st }}$ century. Between booms and busts, up we go!

Follow me on Facebook, Google+, and Twitter.

Moshe Y. Vardi, EDITOR-IN-CHIEF

Copyright held by author. 